\title{
TWO-PHASE DETERIORATED SUPPLY CHAIN MODEL WITH VARIABLE DEMAND AND IMPERFECT PRODUCTION PROCESS UNDER TWO-STAGE CREDIT FINANCING
}

\author{
Brojeswar PaL ${ }^{1}$, Anindya Mandal ${ }^{2}$ and Shib Sankar Sana ${ }^{3, *}$
}

\begin{abstract}
In this article, an imperfect production inventory model consisting of a manufacturer and a retailer with quality improvement effort and the promotional effort sensitive demand pattern is investigated under a two-tier credit policy. We study the model for deteriorating items where the deterioration occurs at different rates in the manufacturer's and the retailer's level considering a fixed lifetime of the product. Discussing the six possible cases of credit policy analytically, we analyze the behavior of the model under an integrated system concerning production lot-size, quality effort and promotional effort such that the integrated average profit is maximum. To obtain the optimal solutions of the model, we design an operative solution algorithm. A numerical example is provided to test feasibility of the model, and the effect of the variation of the key parameters is also studied. The outcomes of this proposed model show that the manufacturer and the retailer have to be more careful about their offered credit periods in aspect of the profit. It is observed that the integrated profit is maximum when both credit periods provided by the manufacturer and the retailer belong to the manufacturer's cycle. Moreover, we identify that the extended product lifetime does not meet with higher profit all times. This study directs that quality effort and promotional effort stimulate the market demand while it is not always economically profitable for the supply chain.
\end{abstract}

Mathematics Subject Classification. 90B05.

Received September 23, 2020. Accepted January 15, 2021.

\section{INTRODUCTION}

In the present day, each business organization takes some useful strategies to survive in the competitive market and smooth functioning of their business. The quality of a product is an essential factor to sell the product. A right quality product fulfils customer satisfaction as well as increase the loyalty of the customer. Nowadays, buyers can put their valuable opinions or comments (either positive or negative) about a product on social media. Therefore, the production companies need to take a strategy to maintain the product quality since the better quality product has a more positive impact on the market. The deterioration effect is also a significant issue in a production inventory system of deteriorated products. We are all well aware about

Keywords. Supply chain model, imperfect production, quality improvement effort, promotional effort, deterioration, trade credit.

1 Department of Mathematics, The University of Burdwan, Burdwan 713104, India.

2 Department of Mathematics, Tehatta Sadananda Mahavidyalaya, Tehatta, Purba Bardhaman 713122, India.

3 Department of Mathematics, Kishore Bharati Bhagini Nivedita College, Ramkrishna Sarani, Behala, Kolkata 700060, India.

*Corresponding author: shib_sankar@yahoo.com 
the fact that items like volatile liquids, blood banks, medicines, electronics components, fashion goods, fruits, vegetables, foodstuff, etc. are deteriorated due to evaporation, obsolescence, spoilage, damage, dryness, etc. during their standard storage period. Therefore, in any business related to those products, it is necessary to control and maintain the deteriorated inventory; otherwise, the values of the products decrease with time. In real-life production inventory systems, some proportion of imperfect quality items are produced due to labour issues, weather issues, deterioration of machine equipment and other controllable and/or uncontrollable matters. The advertisement for the product is one of the key influenced factors of market demand. Generally, advertising or promotion can be done through various channels viz. newspaper, television, posters, banners, wall writing, internet, etc. The main target of advertisement is to attract the customers for the newly launched as well as already running products with various features so that the demand can be raised. That's why the market for a product may be dependent or sensitive to an advertisement for the product. At present, every sector of business, trade credit policy is widely used by the companies. In this policy, the up-stream, i.e., supplier or manufacturer or retailer provides or offers a fixed period, i.e., credit period to the down-stream, i.e., manufacturer or retailer or end customer, after which necessarily the repayment is made partially or fully. When the credit period is over and if the down-stream fails to pay the payable amount, interest is charged. During the permissible period or credit period, the manufacturer or the retailer sells items to the down-stream and accumulate revenues, which could be used to another business purpose or might be invested for investment purpose. By offering trade credit, a company can reduce the holding cost of the products as the maximum number of buyers try to avail of the benefits of the credit period.

In view of the above issues, a production-based two-phase supply chain model of perishable products is considered under two-tier trade credit financing. We consider that value of the perishable product declines over time and has a fixed lifetime. We include product quality and promotional effort sensitive demand throughout the chain for the sake of customers' preference. In this study, we try to seek answers to the following questions: (1) What is the optimal lot-size, quality effort of the manufacturer for economic benefit? (2) What is the retailer's optimal strategy on promotional step towards his/her profit? (3) How the several cost viz. deterioration cost, promotional cost, quality maintain cost influenced the supply chain? (4) How the promotional cost coefficient and quality effort cost coefficient have impact on the demand and the profit?

The remaining part of this paper is designed as follows: Section 2 includes a brief review of related past literature. Section 3 describes the problem definition, notation, and assumptions, which are used to formulate the model. Model formulation, along with the solution procedure, is included in Section 4. Numerical examples are given in Section 5 to illustrate the model. In Section 6, sensitivity analysis is provided with managerial insight. At last, Section 7 concludes the paper with directions for further research.

\section{Literature REVIEW}

Our present study mainly focuses on the research related to the literature of production of perishable item, quality and promotion sensitive product demand, and trade credit policy. We survey the below past research studies based on the mentioned aspects. Krishnan et al. [14] investigated the coordinating contracts for decentralized supply chains for a single product with retailer promotional effort. Later, Chung et al. [8] studied the problem of determining the economic order quantity under conditions of permissible delay in payments where the delay in payments depends on the quantity ordered. After that, Huang [11] formulated an economic production quantity model (EPQ) under two levels of trade credit policy and investigate the optimal retailer's replenishment decisions. Thereafter, Sana and Chaudhuri [35] developed an economic order quantity (EOQ) model with delays in payments and price-discount offers by considering the retailer's profit maximizing strategy. Teng and Chang [44] extended the Huang [11]'s model by introducing the two level trade credit policy in an EPQ model and found the optimal manufacturer's replenishment policies. In the same year, Thangam and Uthayakumar [45] constructed a supply chain model for perishable items under two-echelon trade credit financing. Later, Sana [33] developed an economic production lot size model with the imperfect production, where the production facility may shifts from the "in-control" state to the "out-of-control" state after certain 
time due to higher production rate and production runtime. Ho [10] proposed supplier-retailer inventory model under two level trade credit policy considerering the price and credit-linked sensitive demand. During the same time, Sana [34] investigated an EOQ model where the demand rate is dependent on selling price and salesmen's initiatives. He also assumed that the replenishment rate depends on the level of stock of the items. Avinadav et al. [2] formulated a inventory model for a perishable item with price and time sensitive demand. They also considered the demand rate which decreases linearly in the selling price and polynomially over the time after replenishment. In the same year, Maa et al. [17] developed a supply chain model with quality and marketing effort dependent demand. They investigated the equilibrium behaviors of the supply chain under three supply chain structures: (a) manufacturer Stackelberg, (b) retailer Stackelberg and (c) vertical Nash. Tsao et al. [48] studied an EPQ model with imperfect production under trade credit. They considered both preventive maintenance and corrective maintenance to increase the system reliability. Cárdenas-Barrón and Sana [4] developed a two echelon supply chain model consisting of a manufacturer and a retailer. They considered promotional efforts/sales teams' initiatives depended demand. Same year, Pal et al. [27] investigated a two echelon imperfect production inventory model with two cycles where the retailer sells only good product with actual price in the first cycle and retailer sells the products with a discount price in the second cycle. Later, Chen and Teng [7] investigated a supply chain model consisting of supplier, retailer, and customer for deteriorating items under up-stream and down-stream trade credit financing. He also adopted the discounted cash flow analysis. Pal et al. [28] examined two-layer supply chain model consisting of one manufacturer and one retailer for a single item. They assumed selling price, quality of the products, and promotional effort sensitive market demand. They also investigated the behavior of the supply chain in light of centralized, manufacturer Stackelberg, conditional manufacturer Stackelberg, retailer Stackelberg, conditional retailer Stackelberg, and vertical Nash model structure. Palanivel and Uthayakumar [31] formulated an EOQ model for deteriorating items with price and advertisement sensitive demand under the effect of inflation over a finite planning horizon. They assumed, shortages where partial backlogging rate is dependent on waiting time for the next replenishment. Shah et al. [41] developed an inventory model under two level trade credit policy. They assumed the retailer can choose strategies between cash discount and order linked trade credit from the supplier. Later, Taleizadeh et al. [42] studied an EPQ model with both up-stream and down-stream trade credits. They assumed imperfect production process where all defective items become perfect after reworking process. Tiwari et al. [46] formulated a two warehouse inventory model for deteriorating items with permissible delay in payments under considering partial backlogging. Tsao and Linh [47] designed a supply chain network model for deteriorating items under the conditions of trade credit and partial back-ordering. Wu et al. [52] studied a supplier-retailer-customer supply chain model for deteriorating items with maximum lifetime, where the retailer gets an up-stream full trade credit from the supplier whereas offers a down-stream partial trade credit to the customers. Jaggi et al. [13] investigated a two warehouse inventory model for non-instantaneous deteriorating items under trade credit where where the demand is sensitive to the selling price and shortages are completely backlogged. Maihami et al. [18] established an inventory control model for non-instantaneous deteriorating products with partially backlogging shortage under two echelon trade credit. They also assumed price-dependent probabilistic demand rate and probabilistic deterioration functions. Singh and Sharma [40] formulated a reliable production inventory model for deteriorating items with stochastic demand under the effect of inflation. They considered the two different cases: without shortage and allowable shortage in the model. Pal [25] developed an imperfect production inventory model with quality of the products dependent market's demand and permissible delay in payments allowing waiting time dependent partial backlogging. Tsao et al. [49] established an economic order quantity model for deteriorating items under trade credit policy where the demand is price sensitive. They introduced two-tier pricing and ordering policies where the prices for the non-deteriorating period and the deteriorating period are different. Zhang et al. [54] investigated an EOQ model under two-level credit financing where the retailer receives a partial trade credit from the supplier, and offers a full or partial trade credit to the good or bad credit customers. Mandal and Pal [20] formulated an imperfect production based inventory model with product advertisement and credit period sensitive demand under two-stage trade credit policy. They derived optimal strategies on selling price, advertisement frequency and offered credit time to achieve maximum integrated profit. Among other researches, 
the noteworthy works of Teng and Chang [43], Pal et al. [26], Wu et al. [51], Bai et al. [3], Cárdenas-Barrón and Sana [5], Pal et al. [29], Yang et al. [53], Lashgari et al. [15], Pal et al. [30], Chen [6], Hlioui et al. [9], Sarkar et al. [37], Rad et al. [32], Ahmed and Sarkar [1], Iqbal and Sarkar [12], Mandal and Pal [19], Noh et al. [24], Lou et al. [16], Mishra et al. [22], Nandra et al. [23], Sarkar et al. [39], Ullah and Sarkar [50] should be mentioned.

Table 1 provides a comparison of this work with previous researches.

From the survey of past researches and Table 1, we identify the following research gaps: (1) Most of the previous researcher considers deterioration in the supply chain without production and fixed lifetime of the product, whereas we study the production of a fixed lifetime based deteriorated products in the two-layer supply chain. (2) Few authors include quality effort and promotional effort but not in the deteriorated supply chain, while we consider the quality of product and promotion in a chain framework of perishable items. (3) Moreover, we analyze the chain behaviour considering the mentioned aspects under different cases of trade credit policy.

Novelty and main contribution of this article are: (1) Formulation of a two-echelon production based supply chain model for the deteriorating products under the two-tier trade credit policy. (2) Inclusion of quality improvement effort (QIE) and promotional effort sensitive demand at both the manufacturer and retailer level. (3) Addition of time-dependent deterioration rate. (4) Incorporation of different deterioration rates at the different echelon along with the fixed lifetime of the deteriorated items. (5) Analysis of the model under various cases of credit financing.

The main objective of this paper is to construct the integrated profit function of the supply chain under several cases of credit policy and to determine the optimal strategies on production lot-size, QIE, and promotional effort towards a profit maximization situation.

\section{Problem Definition, notations, And Assumptions}

\subsection{Problem definition}

It is familiar that the perishable product plays a crucial role in a deteriorated supply chain model. Deterioration is a common phenomenon for some products such as food items, drugs, chemicals, etc. The products deteriorate over time and lost their value after a fixed lifetime. Therefore, it is crucial to maintain a proper inventory of perishable products for balancing cost with profit. Moreover, to avoid the sales margin of perishable products, promoting products and offering trade credit could be fruitful tools for any business organizations. Again, the quality of a product is a severe demandable factor for product sell as most customers prefer product quality while purchasing. Keeping the addressed problem in mind, we construct a deteriorated supply chain model with imperfect production under two-level credit policies. Here, the manufacturer produces both the good and defective items and the produced items have a fixed lifetime. The deterioration occurs at different rates in the manufacturer and the retailer level. Deterioration of the product is time-dependent and after the fixed lifetime, the items are totally deteriorated. The demand of the retailer as well as of the customer are sensitive to the QIE and the promotional effort of the product. In this model, both the manufacturer and the retailer offer a fixed credit period to their down-stream to pay out. Now, the problem is to formulate an integrated average profit function and to find out the optimal lot size, optimal QIE, and optimal promotional effort by maximizing the integrated profit.

\subsection{Notations}

We use the following notations throughout the paper.

\section{Decision variables}

$Q$ Total produced items.

$q$ QIE level of the product. Here, $0<q<1$.

$\rho$ Promotional effort level of the product. Here, $0<\rho<1$. 


\section{Parameters}

$P$ Production rate per unit time.

$\alpha$ Percentage of imperfect production.

$D_{r}(q, \rho)$ Rate of demand per unit time of the retailer.

$D_{c}(q, \rho)$ Rate of demand per unit time of the customer.

$s_{m}$ Selling price (\$) per unit item of the manufacturer $\left(s_{m}>C_{m}\right)$.

$s_{r}$ Selling price $(\$)$ per unit item of the retailer $\left(s_{r}>s_{m}\right)$.

$\theta^{\prime}$ Deterioration rate per unit time of the products in the manufacturer cycle.

$\theta^{\prime \prime}$ Deterioration rate per unit time of the products in the retailer cycle.

$L$ Maximum life time of the deteriorating product.

$w$ Cost of deterioration (\$) which is same in the manufacturer and the retailer level.

$C_{m}$ Material cost (\$) per unit item of the manufacturer.

$H_{M}$ Holding cost (\$) per unit perfect item per unit time for the manufacturer.

$H_{R}$ Holding cost $(\$)$ per unit item per unit time for the retailer.

$F_{c}$ Fixed cost $(\$)$ (labor cost, energy cost, maintenance cost, etc.) per cycle of the manufacturer.

$C(Q)$ Production cost (\$) per unit item of the manufacturer.

$M$ Offered credit period to the retailer by the manufacturer.

$N$ Offered credit period to the customer by the retailer.

$I_{c}$ Rate of interest charged (\$ per annum).

$I_{e}$ Interest earned rate (\$ per annum).

$t_{1}$ Production run-time.

$T^{\prime}$ Cycle length of the manufacturer.

$T$ Cycle length of the retailer.

\subsection{Assumptions}

Following assumptions are adopted to develop this model.

(i) Production rate $P$ is constant and known. Here, we consider $(P-\alpha P)>D_{r}$ to avoid shortages.

(ii) We assume that the retailer can influence the demand by providing promotional effort with cost of $k Q \rho^{2}$ [14], where $\rho$ is the effort level and $k$ is the promotion cost coefficient, and the manufacturer can increase the market demand by exerting quality effort with its cost at effort level $q$ is $\xi Q q^{2}$, where the quality cost coefficient is $\xi$.

(iii) Demand of both the retailer and the customer are dependent on the quality effort $(q)$ and promotional effort $(\rho)$ with $D_{r}(q, \rho)=\mu+\eta q+\delta \rho$ and $D_{c}(q, \rho)=\lambda+\eta q+\delta \rho$ respectively, where $\mu>0$ and $\lambda>0$ are the corresponding base market size. To avoid shortages, we also assume $D_{r}>D_{c}$, i.e. $\mu>\lambda . \eta>0$ measures the impact of quality efforts on demand by the manufacturer and $\delta>0$ measures the influence of promotional efforts on demand by the retailer [17].

(iv) The deterioration rates $\theta^{\prime}$ and $\theta^{\prime \prime}$ at the manufacturer's and retailer's level are time dependent and are considered as $\theta^{\prime}=\frac{\theta_{1}}{\theta_{1}+L-t}$ and $\theta^{\prime \prime}=\frac{\theta_{2}}{\theta_{2}+L-t}$, where $\theta_{1}, \theta_{2}$ are constant. We assume deterioration rate at retailer level is greater than of manufacturer level, i.e. $\theta^{\prime \prime}>\theta^{\prime}>0$ which indicates $\theta_{2}>\theta_{1}>0$. Here, $L>t$ and $L$ is the maximum lifetime of the products. When $t \rightarrow L, \theta^{\prime} \rightarrow 1$ and $\theta^{\prime \prime} \rightarrow 1$.

(v) Manufacturer provides a fixed time period $M$ to the retailer to pay out; if the payment is not done within the permissible time period, the interest is charged at a rate $I_{c}$ for due payment of the remaining stock items of the retailer. In the retailer's turn, the retailer also provides a fixed credit time period $N$ to the end customer and earns interest at a rate $I_{e}$ on the revenue collected from the sold items within the offered credit period by the manufacturer [20].

(vii) The unit production cost is assumed $C(Q)=C_{m}+\frac{F_{C}}{Q}, F_{C}>0$, where $C_{m}$ is the material cost per unit item and $F_{C}$ is the fixed cost which includes ordering cost, labor cost, energy cost, and maintenance cost, etc. [33]. 


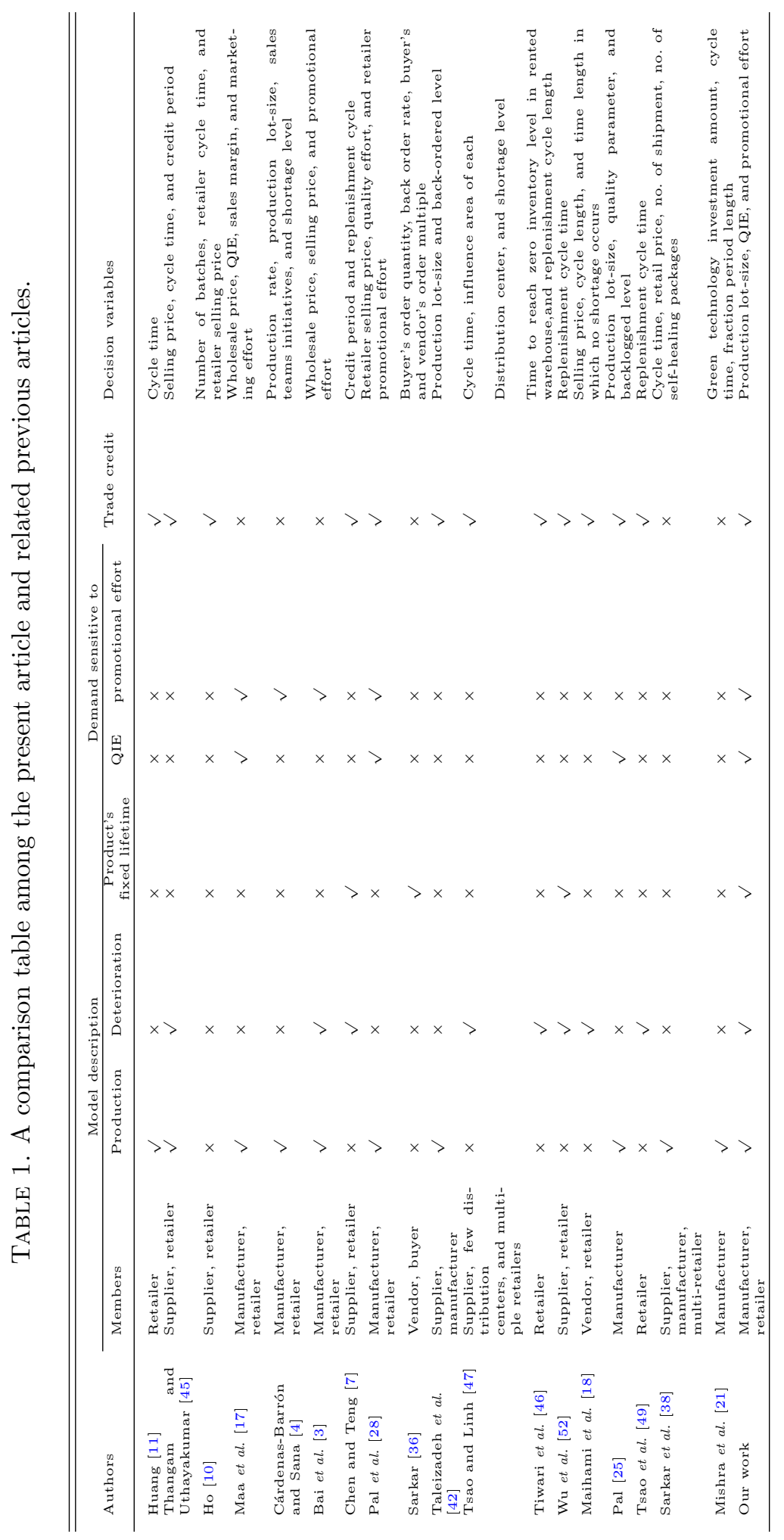




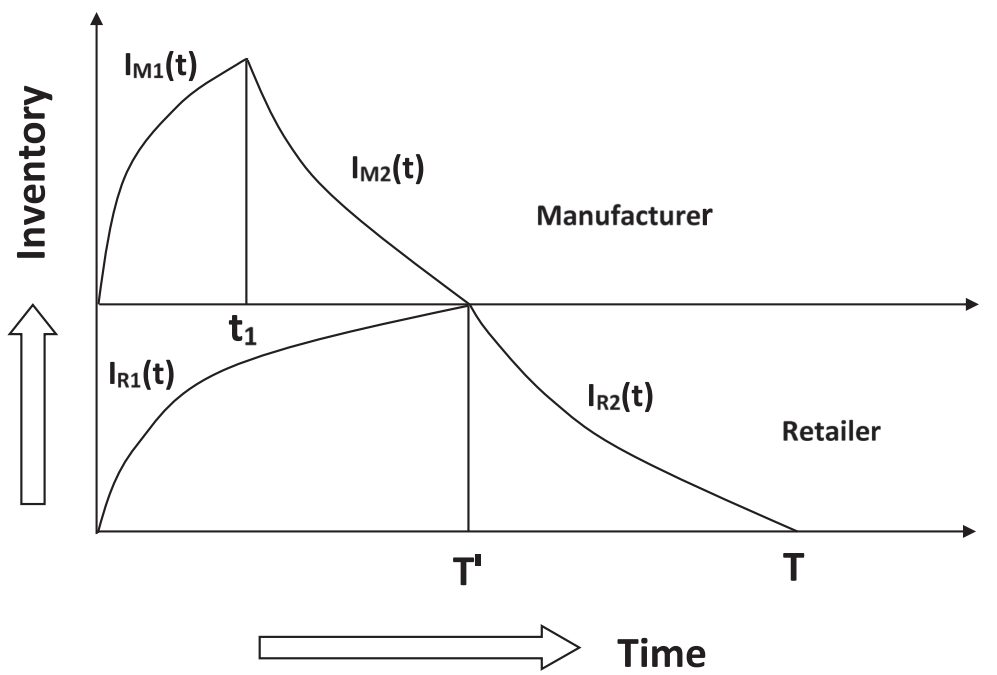

FIGURE 1. Inventory versus time of the manufacturer and the retailer.

\section{Formulation of THE MODEL}

In the supply chain, the manufacturer produces items from the raw materials, and the retailer sells those products to the end customers. Here, the production starts at a rate $P$ and continues up-to-the time $t_{1}$. During the time $t_{1}$, the manufacturer produces both perfect and imperfect products. The production rate of the defective items is $\alpha P$ throughout the production runtime. The produced imperfect products are discarded since the products are both imperfect and deteriorated with time. After time $t_{1}$, the manufacturer's inventory level starts to decrease due to the combined effect of the retailer's demand and the deterioration of the products and reaches zero at time $T^{\prime}$. During the time period $\left[0, T^{\prime}\right]$, the deterioration of the product occurs at a rate $\theta^{\prime}$.

On the other hand, the retailer receives the produced products from the manufacturer up-to-the time $T^{\prime}$ and fulfils the demand of the customers. During the time interval $\left[0, T^{\prime}\right]$, receiving of the produced products and fulfilment of the customers' demand, both the events occur simultaneously. After time $T^{\prime}$, the retailer's inventory level starts to deplete due to the combined effect of the customer demand and the deterioration of the products and reaches zero at time $T$. The product's deterioration rate throughout the retailer's cycle is $\theta^{\prime \prime}$.

The graphical representation of the model is shown in the Figure 1.

\subsection{Manufacturer's individual average profit}

The governing differential equations of on-hand inventory of the manufacturer at time $t$ are:

$$
\frac{I_{M 1}(t)}{\mathrm{d} t}+\theta^{\prime} I_{M 1}(t)=P-\alpha P-D_{r} \quad \text { with } \quad I_{M 1}(0)=0, \quad 0 \leq t \leq t_{1}
$$

and

$$
\frac{I_{M 2}(t)}{\mathrm{d} t}+\theta^{\prime} I_{M 2}(t)=-D_{r} \quad \text { with } \quad I_{M 2}\left(T^{\prime}\right)=0, \quad t_{1} \leq t \leq T^{\prime} .
$$

After solving the differential equations by using the boundary conditions, the solutions are

$$
I_{M 1}(t)=\left(\theta_{1}+L-t\right)\left(P-\alpha P-D_{r}\right) \log \left(\frac{\theta_{1}+L}{\theta_{1}+L-t}\right), \quad 0 \leq t \leq t_{1}
$$


and

$$
I_{M 2}(t)=\left(\theta_{1}+L-t\right) D_{r} \log \left(\frac{\theta_{1}+L-t}{\theta_{1}+L-T^{\prime}}\right), \quad t_{1} \leq t \leq T^{\prime}
$$

At $t_{1}, I_{M 1}\left(t_{1}\right)=I_{M 2}\left(t_{1}\right)$.

Therefore,

$$
\left(\theta_{1}+L-t_{1}\right)\left(P-\alpha P-D_{r}\right) \log \left(\frac{\theta_{1}+L}{\theta_{1}+L-t_{1}}\right)=\left(\theta_{1}+L-t_{1}\right) D_{r} \log \left(\frac{\theta_{1}+L-t_{1}}{\theta_{1}+L-T^{\prime}}\right) .
$$

After simplifying, we get

$$
T^{\prime}=\left(\theta_{1}+L\right)-\left(\theta_{1}+L-t_{1}\right)^{\frac{P-\alpha P}{D_{r}}}\left(\theta_{1}+L\right)^{\theta_{1}-\frac{P-\alpha P}{D_{r}}} .
$$

Let, $Q$ be the total produced items in time $t_{1}$. Then, $t_{1}=\frac{Q}{P}$.

Number of deteriorated items during the time $\left[0, T^{\prime}\right]$ for the manufacturer is $\left(Q-D_{r} T^{\prime}\right)$.

Now, holding cost for the manufacturer is

$$
\begin{aligned}
= & H_{M}\left(\int_{0}^{t_{1}} I_{M 1}(t) \mathrm{d} t+\int_{t_{1}}^{T^{\prime}} I_{M 2}(t) \mathrm{d} t\right) \\
= & H_{M}\left[\frac{1}{4}\left(P-\alpha P-D_{r}\right)\left(\left(\theta_{1}+L\right)^{2}-\left(\theta_{1}+L-t_{1}\right)^{2}\left(1+2 \log \left(\frac{\theta_{1}+L}{\theta_{1}+L-t_{1}}\right)\right)\right)\right. \\
& \left.+\frac{1}{4} D_{r}\left(\left(\theta_{1}+L-T^{\prime}\right)^{2}-\left(\theta_{1}+L-t_{1}\right)^{2}\left(1-2 \log \left(\frac{\theta_{1}+L-t_{1}}{\theta_{1}+L-T^{\prime}}\right)\right)\right)\right] .
\end{aligned}
$$

Deterioration cost of the manufacturer is $w\left(Q-\alpha Q-D_{r} T^{\prime}\right)$.

Cost of QIE for the manufacturer is $\xi Q q^{2}$.

Production cost of the manufacturer is $Q\left(C_{m}+\frac{F_{C}}{Q}\right)$.

Revenue from sale of the manufacturer is $s_{m} D_{r} T^{\prime}$.

Total profit of the manufacturer is

$\mathrm{TPM}=$ Revenue from sales - Production cost - Holding cost - Deterioration cost - Cost of QIE

$$
\begin{aligned}
= & s_{m} D_{r} T^{\prime} \\
& -Q\left(C_{m}+\frac{F_{C}}{Q}\right)-H_{M}\left[\frac{1}{4}\left(P-\alpha P-D_{r}\right)\left(\left(\theta_{1}+L\right)^{2}-\left(\theta_{1}+L-t_{1}\right)^{2}\left(1+2 \log \left(\frac{\theta_{1}+L}{\theta_{1}+L-t_{1}}\right)\right)\right)\right. \\
& \left.+\frac{1}{4} D_{r}\left(\left(\theta_{1}+L-T^{\prime}\right)^{2}-\left(\theta_{1}+L-t_{1}\right)^{2}\left(1-2 \log \left(\frac{\theta_{1}+L-t_{1}}{\theta_{1}+L-T^{\prime}}\right)\right)\right)\right]-w\left(Q-\alpha Q-D_{r} T^{\prime}\right)-\xi Q q^{2} .
\end{aligned}
$$


Therefore, the average profit of the manufacturer is

$$
\begin{aligned}
\mathrm{APM}= & \frac{1}{T}\left[s_{m} D_{r} T^{\prime}-Q\left(C_{m}+\frac{F_{C}}{Q}\right)\right. \\
& -H_{M}\left[\frac{1}{4}\left(P-\alpha P-D_{r}\right)\left(\left(\theta_{1}+L\right)^{2}-\left(\theta_{1}+L-t_{1}\right)^{2}\left(1+2 \log \left(\frac{\theta_{1}+L}{\theta_{1}+L-t_{1}}\right)\right)\right)\right. \\
& \left.+\frac{1}{4} D_{r}\left(\left(\theta_{1}+L-T^{\prime}\right)^{2}-\left(\theta_{1}+L-t_{1}\right)^{2}\left(1-2 \log \left(\frac{\theta_{1}+L-t_{1}}{\theta_{1}+L-T^{\prime}}\right)\right)\right)\right] \\
& \left.-w\left(Q-\alpha Q-D_{r} T^{\prime}\right)-\xi Q q^{2}\right] .
\end{aligned}
$$

\subsection{Retailer's individual average profit}

The governing differential equations of on-hand inventory of the retailer at time $t$ are:

$$
\frac{I_{R 1}(t)}{\mathrm{d} t}+\theta^{\prime \prime} I_{R 1}(t)=D_{r}-D_{c} \quad \text { with } \quad I_{R 1}(0)=0, \quad 0 \leq t \leq t_{1}
$$

and

$$
\frac{I_{R 2}(t)}{\mathrm{d} t}+\theta^{\prime \prime} I_{R 2}(t)=-D_{c} \quad \text { with } \quad I_{R 2}(T)=0, \quad T^{\prime} \leq t \leq T .
$$

After solving the differential equations by using the boundary conditions, the solutions are

$$
I_{R 1}(t)=\left(\theta_{2}+L-t\right)\left(D_{r}-D_{c}\right) \log \left(\frac{\theta_{2}+L}{\theta_{2}+L-t}\right), \quad 0 \leq t \leq T^{\prime}
$$

and

$$
I_{R 2}(t)=\left(\theta_{2}+L-t\right) D_{c} \log \left(\frac{\theta_{2}+L-t}{\theta_{2}+L-T}\right), \quad T^{\prime} \leq t \leq T
$$

Now,

$$
I_{R 1}\left(T^{\prime}\right)=I_{R 2}\left(T^{\prime}\right) \Rightarrow\left(\theta_{2}+L-T^{\prime}\right)\left(D_{r}-D_{c}\right) \log \left(\frac{\theta_{2}+L}{\theta_{2}+L-T^{\prime}}\right)=\left(\theta_{2}+L-T^{\prime}\right) D_{c} \log \left(\frac{\theta_{2}+L-T^{\prime}}{\theta_{2}+L-T}\right) .
$$

Simplification form of the above expression is

$$
T=\left(\theta_{2}+L\right)-\left(\theta_{2}+L-T^{\prime}\right)^{\frac{D_{r}}{D_{c}}}\left(\theta_{2}+L\right)^{1-\frac{D_{r}}{D_{c}}} .
$$

Again, the number of deteriorated items during the time $[0, T]$ for the retailer is $\left(D_{r} T^{\prime}-D_{c} T\right)$.

The holding cost for the retailer is

$$
\begin{aligned}
= & H_{R}\left(\int_{0}^{T^{\prime}} I_{R 1}(t) \mathrm{d} t+\int_{T^{\prime}}^{T} I_{R 2}(t) \mathrm{d} t\right) \\
= & H_{R}\left[\frac{1}{4}\left(D_{r}-D_{c}\right)\left(\left(\theta_{2}+L\right)^{2}-\left(\theta_{2}+L-T^{\prime}\right)^{2}\left(1+2 \log \left(\frac{\theta_{2}+L}{\theta_{2}+L-T^{\prime}}\right)\right)\right)\right. \\
& \left.+\frac{1}{4} D_{c}\left(\left(\theta_{2}+L-T\right)^{2}-\left(\theta_{2}+L-T^{\prime}\right)^{2}\left(1-2 \log \left(\frac{\theta_{2}+L-T^{\prime}}{\theta_{2}+L-T}\right)\right)\right)\right] .
\end{aligned}
$$


Deterioration cost for the retailer is $w\left(D_{r} T^{\prime}-D_{c} T\right)$.

Cost of promotional effort for the retailer is $k Q \rho^{2}$.

Set-up cost for the retailer is $A_{r}$.

Revenue from sale of the retailer is $s_{r} D_{c} T$.

Total profit of the retailer is

$\mathrm{TPR}=$ Revenue from sales - Set-up cost - Deterioration cost - Holding cost - Cost of promotional effort $=s_{r} D_{c} T-A_{r}-w\left(D_{r} T^{\prime}-D_{c} T\right)$

$$
\begin{aligned}
& -H_{R}\left[\frac{1}{4}\left(D_{r}-D_{c}\right)\left(\left(\theta_{2}+L\right)^{2}-\left(\theta_{2}+L-T^{\prime}\right)^{2}\left(1+2 \log \left(\frac{\theta_{2}+L}{\theta_{2}+L-T^{\prime}}\right)\right)\right)\right. \\
& \left.+\frac{1}{4} D_{c}\left(\left(\theta_{2}+L-T\right)^{2}-\left(\theta_{2}+L-T^{\prime}\right)^{2}\left(1-2 \log \left(\frac{\theta_{2}+L-T^{\prime}}{\theta_{2}+L-T}\right)\right)\right)\right]-k Q \rho^{2} .
\end{aligned}
$$

Therefore, the average profit of the retailer is

$$
\begin{aligned}
\mathrm{APR}= & \frac{1}{T}\left[s_{r} D_{c} T-A_{r}-w\left(D_{r} T^{\prime}-D_{c} T\right)\right. \\
& -H_{R}\left[\frac{1}{4}\left(D_{r}-D_{c}\right)\left(\left(\theta_{2}+L\right)^{2}-\left(\theta_{2}+L-T^{\prime}\right)^{2}\left(1+2 \log \left(\frac{\theta_{2}+L}{\theta_{2}+L-T^{\prime}}\right)\right)\right)\right. \\
& \left.\left.+\frac{1}{4} D_{c}\left(\left(\theta_{2}+L-T\right)^{2}-\left(\theta_{2}+L-T^{\prime}\right)^{2}\left(1-2 \log \left(\frac{\theta_{2}+L-T^{\prime}}{\theta_{2}+L-T}\right)\right)\right)\right]-k Q \rho^{2}\right] .
\end{aligned}
$$

\subsection{Use of trade credit policy}

We assume that the manufacturer offers a credit period of $M$ to the retailer. Therefore, the manufacturer receives the due payment from the retailer either at the time $M$ if $M>T$ or from the time $M$ if $M \leq T$. As a result, the manufacturer has to pay interest for his associated cost up-to-the time $M$. If the retailer is not able to pay due-payment by the time $M$, the manufacturer simultaneously receives the partial payment and the interest on rest due amount from the retailer after the time $M$.

Here, the interest paid per unit time by the manufacturer is

$$
\mathrm{ICM}= \begin{cases}C_{m} I_{c} D_{r}\left(M-\frac{T}{2}\right), & \text { when } M>T \\ \frac{1}{2 T} C_{m} I_{c} D_{r} M^{2}, & \text { when } M \leq T .\end{cases}
$$

On the other hand, the retailer provides a fixed time period $N$ to the customers to pay the outstanding amount. Therefore, the retailer collects all the revenue either within the cycle time period of $T$ if $N \leq T$ or at time $N$ if $N>T$.

We assume that the credit time period offered by the manufacturer is greater than or equal to the credit period provided by the retailer i.e. $N \leq M$.

Depending on the values of $M, T^{\prime}$, and $T$ the following possible cases are considered:

Case 1. $N \leq M \leq T^{\prime} \leq T$.

In this case, the retailer does not give any payment up-to-the time $M$. As a result, the retailer earns interest at a rate of $I_{e}$ on the revenue collected from sold items from the time period $N$ to $M$. As the retailer does not sell all the items by the time $M$, he/she has to pay interest at a rate $I_{c}$ on the items rest in stock from the time period $M$ to $T$ (see Fig. 2). 

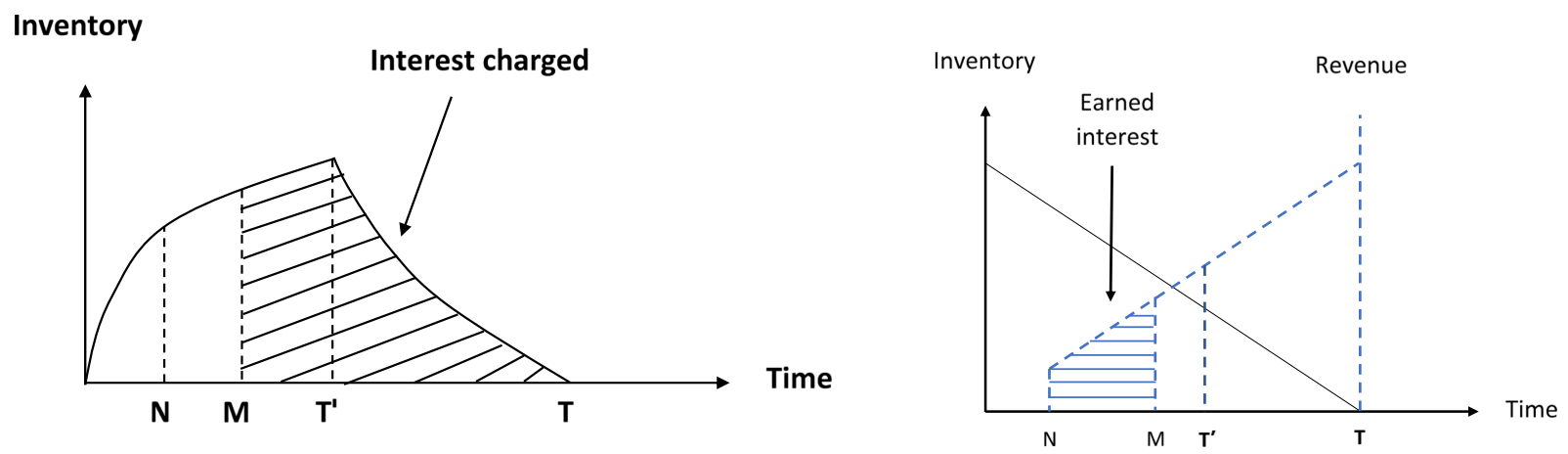

FiguRE 2. Interest charged and earned amount of the retailer when $N \leq M \leq T^{\prime} \leq T$.

So, the interest earned per unit time by the retailer is

$$
\begin{aligned}
\mathrm{IE}_{r 1} & =\frac{s_{r} I_{e}}{T} \int_{N}^{M} D_{c} t \mathrm{~d} t \\
& =\frac{1}{2 T} s_{r} I_{e} D_{c}\left(M^{2}-N^{2}\right),
\end{aligned}
$$

and the interest charged per unit time from the retailer is

$$
\begin{aligned}
\mathrm{IP}_{r 1}= & \frac{s_{m} I_{c}}{T}\left(\int_{M}^{T^{\prime}} I_{R 1}(t) \mathrm{d} t+\int_{T^{\prime}}^{T} I_{R 2}(t) \mathrm{d} t\right) \\
= & \frac{s_{m} I_{c}}{T}\left[\frac { 1 } { 4 } ( D _ { r } - D _ { c } ) \left(\left(\theta_{2}+L-M\right)^{2}\left(1+2 \log \left(\frac{\theta_{2}+L}{\theta_{2}+L-M}\right)\right)\right.\right. \\
& \left.-\left(\theta_{2}+L-T^{\prime}\right)^{2}\left(1+2 \log \left(\frac{\theta_{2}+L}{\theta_{2}+L-T^{\prime}}\right)\right)\right) \\
& \left.+\frac{1}{4} D_{c}\left(\left(\theta_{2}+L-T\right)^{2}-\left(\theta_{2}+L-T^{\prime}\right)^{2}\left(1-2 \log \left(\frac{\theta_{2}+L-T^{\prime}}{\theta_{2}+L-T}\right)\right)\right)\right] .
\end{aligned}
$$

In this case, the average profit for the manufacturer and the retailer are as follows:

$$
\mathrm{APM}_{1}=\mathrm{APM}-\frac{1}{2 T} C_{m} I_{c} D_{r} M^{2}
$$

and

$$
\mathrm{APR}_{1}=\mathrm{APR}+\mathrm{IE}_{r 1}-\mathrm{IP}_{r 1} .
$$

Now, the integrated average profit for the supply chain is

$$
\begin{aligned}
\mathrm{IAP}_{1} & =\mathrm{APM}_{1}+\mathrm{APR}_{1} \\
& =\frac{1}{2 T} C_{m} I_{c} D_{r} M^{2}+\mathrm{APR}+\mathrm{IE}_{r 1}-\mathrm{IP}_{r 1} .
\end{aligned}
$$

Case 2. $N \leq T^{\prime} \leq M \leq T$. 
Inventory

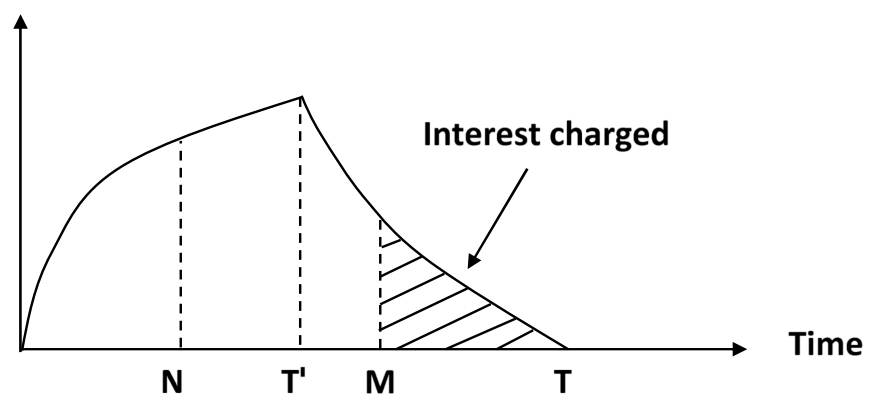

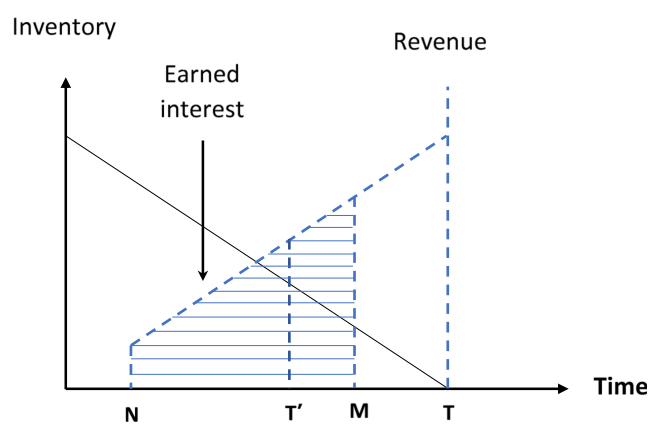

FIgURE 3. Interest charged and earned amount of the retailer when $N \leq T^{\prime} \leq M \leq T$.

In this case, the retailer earns interest at a rate $I_{e}$ on the revenue collected from sold items from the time period $N$ to $M$ and the retailer pays interest at a rate $I_{c}$ on the items rest in stock from the time period $M$ to $T$ (see Fig. 3).

Therefore, the interest earned per unit time by the retailer is

$$
\begin{aligned}
\mathrm{IE}_{r 2} & =\frac{s_{r} I_{e}}{T} \int_{N}^{M} D_{c} t \mathrm{~d} t \\
& =\frac{1}{2 T} s_{r} I_{e} D_{c}\left(M^{2}-N^{2}\right)
\end{aligned}
$$

and the interest charged per unit time from the retailer is

$$
\begin{aligned}
\mathrm{IP}_{r 2} & =\frac{s_{m} I_{c}}{T} \int_{M}^{T} I_{R 2}(t) \mathrm{d} t \\
& =\frac{s_{m} I_{c}}{T}\left[\frac{1}{4} D_{c}\left(\left(\theta_{2}+L-T\right)^{2}-\left(\theta_{2}+L-M\right)^{2}\left(1-2 \log \left(\frac{\theta_{2}+L-M}{\theta_{2}+L-T}\right)\right)\right)\right]
\end{aligned}
$$

In this case, the average profit for the manufacturer and the retailer are as follows:

$$
\mathrm{APM}_{2}=\mathrm{APM}-\frac{1}{2 T} C_{m} I_{c} D_{r} M^{2}
$$

and

$$
\mathrm{APR}_{2}=\mathrm{APR}+\mathrm{IE}_{r 2}-\mathrm{IP}_{r 2}
$$

Now, the integrated average profit for the supply chain is

$$
\begin{aligned}
\mathrm{IAP}_{2} & =\mathrm{APM}_{2}+\mathrm{APR}_{2} \\
& =\mathrm{APM}-\frac{1}{2 T} C_{m} I_{c} D_{r} M^{2}+\mathrm{APR}+\mathrm{IE}_{r 2}-\mathrm{IP}_{r 2} .
\end{aligned}
$$

Case 3. $N \leq T^{\prime} \leq T \leq M$.

In this case, the retailer need not pay any interest. Furthermore, he/she earns interest on the collected revenue of sold items from the time period $N$ to $T$ and receives on full revenue from time $T$ to $M$ (see Fig. 4). 


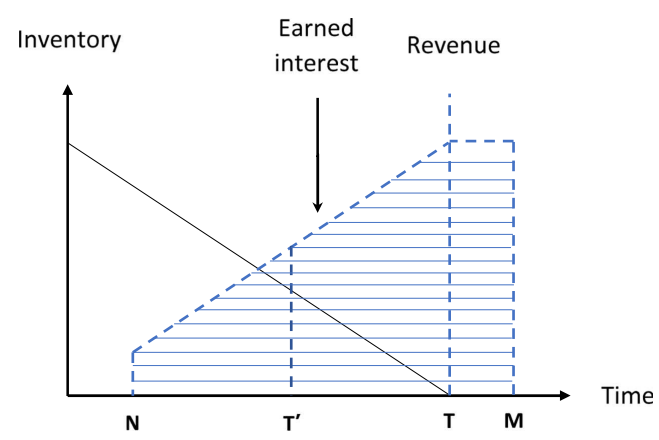

Figure 4. Interest earned amount of the retailer when $N \leq T^{\prime} \leq T \leq M$.

Therefore, the interest earned per unit time by the retailer is

$$
\begin{aligned}
\mathrm{IE}_{r 3} & =\frac{s_{r} I_{e}}{T}\left[\int_{N}^{T} D_{c} t \mathrm{~d} t+D_{c} T(M-T)\right] \\
& =\frac{s_{r} I_{e}}{T}\left[\frac{1}{2} D_{c}\left(T^{2}-N^{2}\right)+D_{c} T(M-T)\right] \\
& =\frac{1}{2 T} s_{r} I_{e} D_{c}\left(2 M T-N^{2}-T^{2}\right) .
\end{aligned}
$$

In this case, the average profit for the manufacturer and the retailer are as follows:

$$
\mathrm{APM}_{3}=\mathrm{APM}-C_{m} I_{c} D_{r}\left(M-\frac{T}{2}\right)
$$

and

$$
\mathrm{APR}_{3}=\mathrm{APR}+\mathrm{IE}_{r 3} .
$$

Now, the integrated average profit for the supply chain is

$$
\begin{aligned}
\mathrm{IAP}_{3} & =\mathrm{APM}_{3}+\mathrm{APR}_{3} \\
& =\mathrm{APM}-C_{m} I_{c} D_{r}\left(M-\frac{T}{2}\right)+\mathrm{APR}+\mathrm{IE}_{r 3} .
\end{aligned}
$$

Case 4. $T^{\prime} \leq N \leq M \leq T$.

In this case, the retailer earns interest from the time period $N$ to $M$ on the revenue collected from sold items. As the retailer does not sell all the items by the period $M$, therefore, the retailer has to pay interest for the items in stock from the time period $M$ to $T$ (see Fig. 5).

So, the interest earned per unit time by the retailer is

$$
\begin{aligned}
\mathrm{IE}_{r 4} & =\frac{s_{r} I_{e}}{T} \int_{N}^{M} D_{c} t \mathrm{~d} t \\
& =\frac{1}{2 T} s_{r} I_{e} D_{c}\left(M^{2}-N^{2}\right)
\end{aligned}
$$




\section{Inventory}
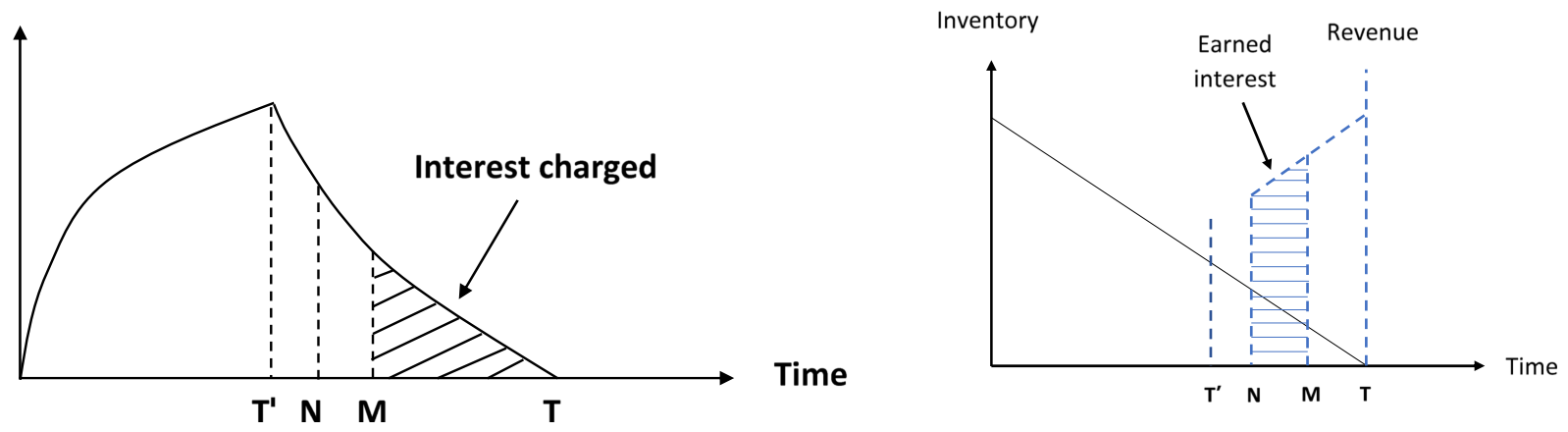

FigURE 5. Interest charged and earned amount of the retailer when $T^{\prime} \leq N \leq M \leq T$.

and the interest charged per unit time from the retailer is

$$
\begin{aligned}
\operatorname{IP}_{r 4} & =\frac{s_{m} I_{c}}{T}\left(\int_{M}^{T} I_{R 2}(t) \mathrm{d} t\right) \\
& =\frac{s_{m} I_{c}}{T}\left[\frac{1}{4} D_{c}\left(\left(\theta_{2}+L-T\right)^{2}-\left(\theta_{2}+L-M\right)^{2}\left(1-2 \log \left(\frac{\theta_{2}+L-M}{\theta_{2}+L-T}\right)\right)\right)\right] .
\end{aligned}
$$

In this case, the average profit for the manufacturer and the retailer are as follows:

$$
\mathrm{APM}_{4}=\mathrm{APM}-\frac{1}{2 T} C_{b} I_{c} D M^{2}
$$

and

$$
\mathrm{APR}_{4}=\mathrm{APR}+\mathrm{IE}_{r 4}-\mathrm{IP}_{r 4}
$$

Now, the integrated average profit for the supply chain is

$$
\begin{aligned}
\mathrm{IAP}_{4} & =\mathrm{APM}_{4}+\mathrm{APR}_{4} \\
& =\mathrm{APM}-\frac{1}{2 T} C_{b} I_{c} D M^{2}+\mathrm{APR}+\mathrm{IE}_{r 4}-\mathrm{IP}_{r 4} .
\end{aligned}
$$

Case 5. $T^{\prime} \leq N \leq T \leq M$.

In this case, the credit period time offered by the manufacturer is greater than the retailer cycle time. Therefore, the retailer need not pay any interest. Moreover, the retailer earns interest on the collected revenue of sold items from time $N$ to $T$ and on the full revenue from the time $T$ to $M$ (see Fig. 6).

Therefore, the interest earned per unit time by the retailer is

$$
\begin{aligned}
\mathrm{IE}_{r 5} & =\frac{s_{r} I_{e}}{T}\left[\int_{N}^{T} D_{c} t \mathrm{~d} t+D_{c} T(M-T)\right] \\
& =\frac{s_{r} I_{e}}{T}\left[\frac{1}{2} D_{c}\left(T^{2}-N^{2}\right)+D_{c} T(M-T)\right] \\
& =\frac{1}{2 T} s_{r} I_{e} D_{c}\left(2 M T-N^{2}-T^{2}\right) .
\end{aligned}
$$




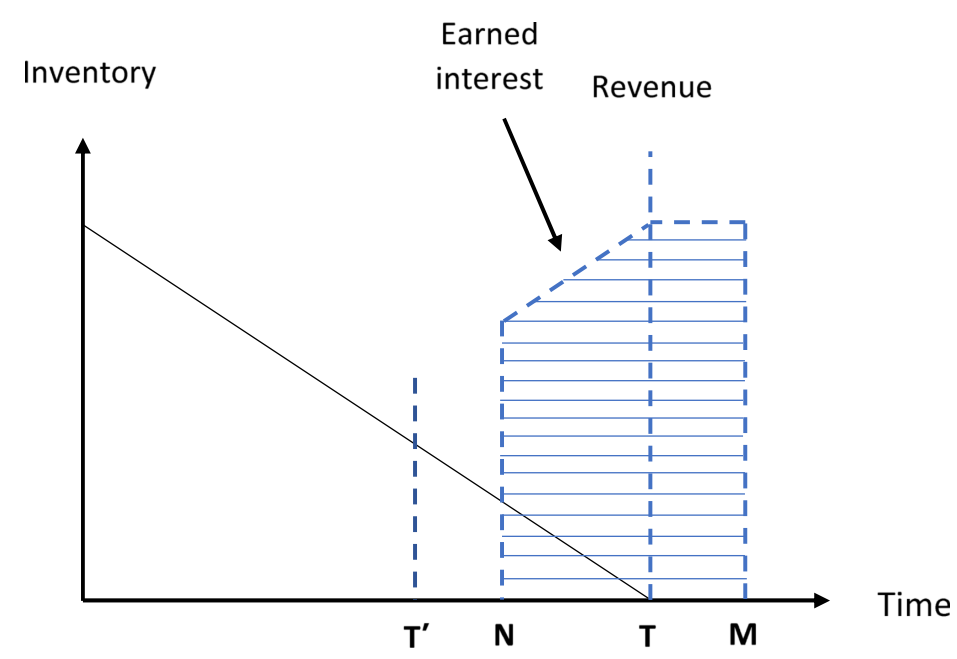

FiguRE 6. Interest earned amount of the retailer when $T^{\prime} \leq N \leq T \leq M$.

In this case, the average profit for the manufacturer and the retailer are as follows:

$$
\mathrm{APM}_{5}=\mathrm{APM}-C_{b} I_{c} D\left(M-\frac{T}{2}\right)
$$

and

$$
\mathrm{APR}_{5}=\mathrm{APR}+\mathrm{IE}_{r 5} .
$$

Now, the integrated average profit for the supply chain is

$$
\begin{aligned}
\mathrm{IAP}_{5} & =\mathrm{APM}_{5}+\mathrm{APR}_{5} \\
& =\mathrm{APM}-C_{b} I_{c} D\left(M-\frac{T}{2}\right)+\mathrm{APR}+\mathrm{IE}_{r 5} .
\end{aligned}
$$

Case 6. $T^{\prime} \leq T \leq N \leq M$.

In this case, both the credit period time offered by the manufacturer and the retailer is greater than the retailer cycle time. Therefore, the retailer earns interest on full revenue from the time $N$ to $M$ (see Fig. 7). Therefore, the interest earned per unit time by the retailer is

$$
\mathrm{IE}_{r 6}=\frac{s_{r} I_{e}}{T}\left[D_{c} T(M-N)\right] .
$$

In this case, the average profit for the manufacturer and the retailer are as follows:

$$
\mathrm{APM}_{6}=\mathrm{APM}-C_{b} I_{c} D\left(M-\frac{T}{2}\right)
$$

and

$$
\mathrm{APR}_{6}=\mathrm{APR}+\mathrm{IE}_{r 6} .
$$

Now, the integrated average profit for the supply chain is

$$
\begin{aligned}
\mathrm{IAP}_{6} & =\mathrm{APM}_{6}+\mathrm{APR}_{6} \\
& =\mathrm{APM}-C_{b} I_{c} D\left(M-\frac{T}{2}\right)+\mathrm{APR}+\mathrm{IE}_{r 6} .
\end{aligned}
$$




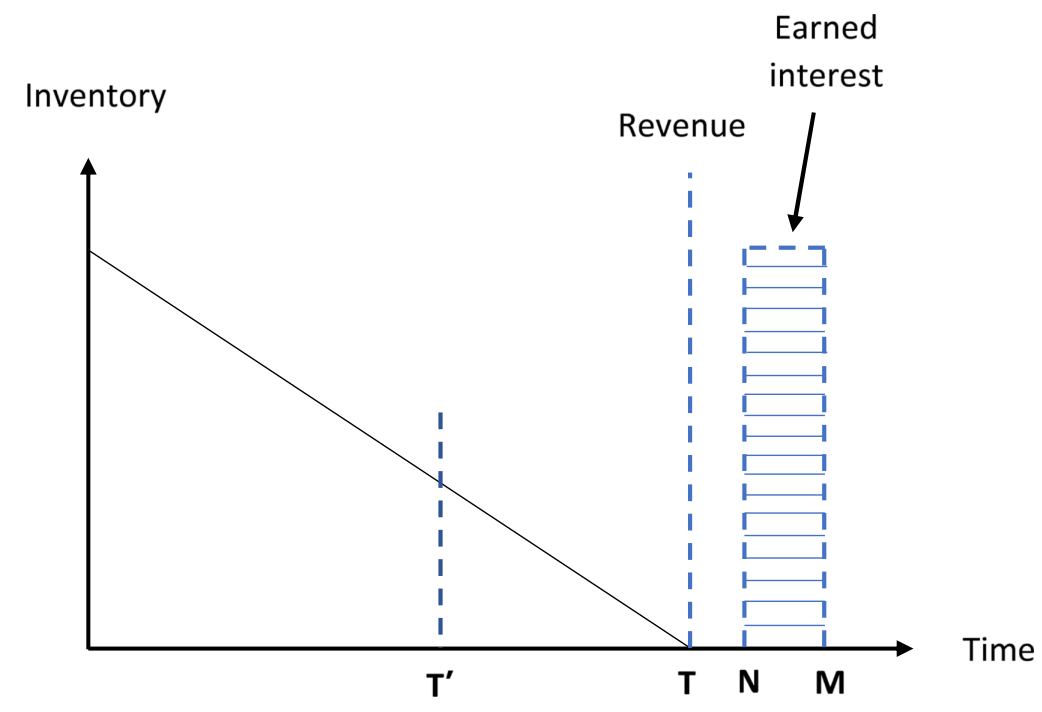

FiguRE 7. Interest earned amount of the retailer when $T^{\prime} \leq T \leq N \leq M$.

\subsection{Integrated average profit}

Integrated average profit for the supply chain is

$$
\mathrm{IAP}=\left\{\begin{array}{lll}
\mathrm{IAP}_{1}=\mathrm{APM}-\frac{1}{2 T} C_{b} I_{c} D M^{2}+\mathrm{APR}+\mathrm{IE}_{r 1}-\mathrm{IP}_{r 1}, & N \leq M \leq T^{\prime} \leq T \\
\mathrm{IAP}_{2}=\mathrm{APM}-\frac{1}{2 T} C_{b} I_{c} D M^{2}+\mathrm{APR}+\mathrm{IE}_{r 2}-\mathrm{IP}_{r 2}, & N \leq T^{\prime} \leq M \leq T \\
\mathrm{IAP}_{3}=\mathrm{APM}-C_{b} I_{c} D\left(M-\frac{T}{2}\right)+\mathrm{APR}+\mathrm{IE}_{r 3}, & N \leq T^{\prime} \leq T \leq M \\
\mathrm{IAP}_{4}=\mathrm{APM}-\frac{1}{2 T} C_{b} I_{c} D M^{2}+\mathrm{APR}+\mathrm{IE}_{r 4}-\mathrm{IP}_{r 4}, & T^{\prime} \leq N \leq M \leq T \\
\mathrm{IAP}_{5}=\mathrm{APM}-C_{b} I_{c} D\left(M-\frac{T}{2}\right)+\mathrm{APR}+\mathrm{IE}_{r 5}, & T^{\prime} \leq N \leq T \leq M \\
\mathrm{IAP}_{6}=\mathrm{APM}-C_{b} I_{c} D\left(M-\frac{T}{2}\right)+\mathrm{APR}+\mathrm{IE}_{r 6}, & T^{\prime} \leq T \leq N \leq M .
\end{array}\right.
$$

Substituting the values of APM, APR, IE $\mathrm{IE}_{r 1}, \mathrm{IP}_{r 1}, \mathrm{IE}_{r 2}, \mathrm{IP}_{r 2}, \mathrm{IE}_{r 3}, \mathrm{IP}_{r 3}, \mathrm{IE}_{r 4}, \mathrm{IP}_{r 4}, \mathrm{IE}_{r 5}, \mathrm{IP}_{r 5}, \mathrm{IE}_{r 6}, \mathrm{IP}_{r 6}$, $t_{1}=\frac{Q}{P}, D_{r}(q, \rho)=\mu+\eta q+\delta \rho, D_{c}(q, \rho)=\lambda+\eta q+\delta \rho, T^{\prime}=\left(\theta_{1}+L\right)-\left(\theta_{1}+L-t_{1}\right)^{\frac{P-\alpha P}{D_{r}}}\left(\theta_{1}+L\right)^{1-\frac{P-\alpha P}{D_{r}}}$, and $T=\left(\theta_{2}+L\right)-\left(\theta_{2}+L-T^{\prime}\right)^{\frac{D_{r}}{D_{c}}}\left(\theta_{2}+L\right)^{1-\frac{D_{r}}{D_{c}}}$ respectively, in the above equation (4.5) and after simplifying, the revised form of the average integrated profit for all cases are

$$
\pi(Q, q, \rho)= \begin{cases}\pi_{1}(Q, q, \rho), & N \leq M \leq T^{\prime} \leq T \\ \pi_{2}(Q, q, \rho), & N \leq T^{\prime} \leq M \leq T \\ \pi_{3}(Q, q, \rho), & N \leq T^{\prime} \leq T \leq M \\ \pi_{4}(Q, q, \rho), & T^{\prime} \leq N \leq M \leq T \\ \pi_{5}(Q, q, \rho), & T^{\prime} \leq N \leq T \leq M \\ \pi_{6}(Q, q, \rho), & T^{\prime} \leq T \leq N \leq M\end{cases}
$$




\subsection{Solution procedure}

The integrated average profit function for the Case 1 is

$$
\begin{aligned}
\pi_{1}(Q, q, \rho)= & \frac{1}{T}\left[s_{m} D_{r} T^{\prime}-Q\left(C_{m}+\frac{F_{C}}{Q}\right)-H_{M}\left[\frac { 1 } { 4 } ( P - \alpha P - D _ { r } ) \left(\left(\theta_{1}+L\right)^{2}\right.\right.\right. \\
& \left.-\left(\theta_{1}+L-t_{1}\right)^{2}\left(1+2 \log \left(\frac{\theta_{1}+L}{\theta_{1}+L-t_{1}}\right)\right)\right) \\
& \left.+\frac{1}{4} D_{r}\left(\left(\theta_{1}+L-T^{\prime}\right)^{2}-\left(\theta_{1}+L-t_{1}\right)^{2}\left(1-2 \log \left(\frac{\theta_{1}+L-t_{1}}{\theta_{1}+L-T^{\prime}}\right)\right)\right)\right] \\
& \left.-w\left(Q-\alpha Q-D_{r} T^{\prime}\right)-\xi Q q^{2}\right]+\frac{1}{T}\left[s_{r} D_{c} T-A_{r}-w\left(D_{r} T^{\prime}-D_{c} T\right)\right. \\
& -H_{R}\left[\frac{1}{4}\left(D_{r}-D_{c}\right)\left(\left(\theta_{2}+L\right)^{2}-\left(\theta_{2}+L-T^{\prime}\right)^{2}\left(1+2 \log \left(\frac{\theta_{2}+L}{\theta_{2}+L-T^{\prime}}\right)\right)\right)\right. \\
& \left.\left.+\frac{1}{4} D_{c}\left(\left(\theta_{2}+L-T\right)^{2}-\left(\theta_{2}+L-T^{\prime}\right)^{2}\left(1-2 \log \left(\frac{\theta_{2}+L-T^{\prime}}{\theta_{2}+L-T}\right)\right)\right)\right]-k Q \rho^{2}\right] \\
& +\frac{1}{2 T} s_{r} I_{e} D_{c}\left(M^{2}-N^{2}\right)-\frac{s_{m} I_{c}}{T}\left[\frac { 1 } { 4 } ( D _ { r } - D _ { c } ) \left(\left(\theta_{2}+L-M\right)^{2}\left(\theta_{2}+2 \log \left(\frac{\theta_{2}+L}{\theta_{2}+L-M}\right)\right)\right.\right. \\
& \left.-\left(\theta_{2}+L-T^{\prime}\right)^{2}\left(1+2 \log \left(\frac{\theta_{2}+L}{\theta_{2}+L-T^{\prime}}\right)\right)\right)+\frac{1}{4} D_{c}\left(\left(\theta_{2}+L-T\right)^{2}-\left(\theta_{2}+L-T^{\prime}\right)^{2}\right. \\
& \left.\left.\times\left(1-2 \log \left(\frac{\theta_{2}+L-T^{\prime}}{\theta_{2}+L-T}\right)\right)\right)\right]
\end{aligned}
$$

Our target is to maximize the integrated average profit function $\pi_{1}(Q, q, \rho)$ with respect to the constraints $Q>0,0<q<1$ and $0<\rho<1$ on the optimal strategies of $Q, q$, and $\rho$. We derive the first order and second order derivatives of $\pi_{1}(Q, q, \rho)$ with respect to $Q, q$, and $\rho$. Solving the equations $\frac{\partial \pi_{1}(Q, q, \rho)}{\partial Q}=0, \frac{\partial \pi_{1}(Q, q, \rho)}{\partial q}=0$, and $\frac{\partial \pi_{1}(Q, q, \rho)}{\partial \rho}=0$, we get the values of $Q=Q^{*}, q=q^{*}$, and $\rho=\rho^{*}$. These values will be optimal if the corresponding Hessian matrix of the integrated average profit function is negative definite.

i.e. if all the eigenvalues of the Hessian matrix,

$$
\mathrm{H}=\left(\begin{array}{lll}
\frac{\partial^{2} \pi_{1}(Q, q, \rho)}{\partial Q^{2}} & \frac{\partial^{2} \pi_{1}(Q, q, \rho)}{\partial Q \partial q} & \frac{\partial^{2} \pi_{1}(Q, q, \rho)}{\partial Q \partial \rho} \\
\frac{\partial^{2} \pi_{1}(Q, q, \rho)}{\partial q \partial Q} & \frac{\partial^{2} \pi_{1}(Q, q, \rho)}{\partial q^{2}} & \frac{\partial^{2} \pi_{1}(Q, q, \rho)}{\partial q \partial \rho} \\
\frac{\partial^{2} \pi_{1}(Q, q, \rho)}{\partial \rho \partial Q} & \frac{\partial^{2} \pi_{1}(Q, q, \rho)}{\partial \rho \partial q} & \frac{\partial^{2} \pi_{1}(Q, q, \rho)}{\partial \rho^{2}}
\end{array}\right)_{\left(Q^{*}, q^{*}, \rho^{*}\right)} \text { are negative. }
$$

It is tough to verify the condition analytically for its complicated form. The integrated average profit function for all the cases is highly non-linear and all the first and second-order derivatives of the profit function with respect to $Q, q$ and $\rho$ are too much complicated. That's why the analytical solution is not likely to derive for the integrated average profit function.

Maximum integrated average profit $\pi_{1}^{*}(Q, q, \rho)$ for the Case 1 is obtained by substituting the values of $Q^{*}, q^{*}$, and $\rho^{*}$ in equation (4.7).

In a similar way as done for Case 1, the maximum integrated average profit for the remaining cases of (4.6) can be derived. 
TABLE 2. Optimal outcomes of the numerical example.

\begin{tabular}{llllllllllll}
\hline \hline Cases $1-6$ & $M$ & $N$ & $Q^{*}$ & $q^{*}$ & $\rho^{*}$ & $t_{1}^{*}$ & $T^{*}$ & $T^{*}$ & $\mathrm{APM}_{i}^{*}$ & $\mathrm{APR}_{i}^{*}$ & $\mathrm{IAP}_{i}^{*}$ \\
\hline$N \leq M \leq T^{\prime} \leq T$ & 0.73 & 0.71 & 549.527 & 0.8712 & 0.8188 & 0.6869 & 0.7563 & 0.8743 & $\mathbf{1 5 1 7 9 . 0}$ & 26210.9 & $\mathbf{4 1 3 8 9 . 9}$ \\
$N \leq T^{\prime} \leq M \leq T$ & 0.76 & 0.72 & 530.205 & 0.8621 & 0.8103 & 0.6628 & 0.7306 & 0.8454 & 14537.7 & 26257.5 & 40795.2 \\
$N \leq T^{\prime} \leq T \leq M$ & 1.50 & 1.20 & 907.663 & 0.8640 & 0.8121 & 1.1346 & 1.2368 & 1.4052 & 14632.9 & $\mathbf{2 6 6 6 2 0 . 7}$ & 41253.6 \\
$T^{\prime} \leq N \leq M \leq T$ & 1.50 & 1.40 & 1006.2 & 0.8553 & 0.8038 & 1.2578 & 1.3674 & 1.5459 & 14634.6 & 26211.7 & 40846.4 \\
$T^{\prime} \leq N \leq T \leq M$ & 2.00 & 1.80 & 1323.51 & 0.8544 & 0.8030 & 1.6544 & 1.7789 & 1.9758 & 14838.1 & 26268.3 & 41106.4 \\
$T^{\prime} \leq T \leq N \leq M$ & 3.3 & 3.2 & 2165.07 & 0.8341 & 0.7840 & 2.7063 & 2.7926 & 2.9213 & 14882.7 & 25628.3 & 40511.0 \\
\hline
\end{tabular}

Notes. Bold faces of the values indicate highest values of APM, APR and IAP respectively among the six cases of credit policy.

\subsection{Solution algorithm}

For Case 1: $N \leq M \leq T^{\prime} \leq T$.

Step 1. Put the parameters' value.

Step 2. Compute all the first order and second order partial derivatives of $\pi_{1}(Q, q, \rho)$ with respect to $Q, q$ and $\rho$.

Step 3. Solve the equations $\frac{\partial \pi_{1}(Q, q, \rho)}{\partial Q}=0, \frac{\partial \pi_{1}(Q, q, \rho)}{\partial q}=0$ and $\frac{\partial \pi_{1}(Q, q, \rho)}{\partial \rho}=0$, to find the values of $Q, q$, and $\rho$.

Step 4. Find the the values of $T^{\prime}$ and $T$.

Step 5. If the condition $N \leq M \leq T^{\prime} \leq T$ is satisfied, go to step 6; else go to step 1 .

Step 6. Derive the Hessian matrix $H$.

Step 7. If the Hessian matrix $H$ is negative definite, go to next step; else go to step 1.

Step 8. The values $Q=Q^{*}, q=q^{*}$, and $\rho=\rho^{*}$ in step 3 are the optimal solutions.

Step 9. Compute the integrated average profit $\pi_{1}{ }^{*}(Q, q, \rho)$ by substituting the values of $Q^{*}, q^{*}$, and $\rho^{*}$ in the $\pi_{1}(Q, q, \rho)$.

Step 10. Procedure terminates.

For the others cases, the same algorithm mentioned above to be followed to obtain the integrated average profit functions.

\section{Numerical EXAMPLES}

The parameters value in appropriate units are as follows:

Retailer's set-up cost $\left(A_{r}\right)=\$ 60$, production rate $(P)=800$ units per unit time, percentage of imperfect item production $(\alpha)=0.1 \%$, selling price of the manufacturer $\left(s_{m}\right)=\$ 35$, retailer selling price $\left(s_{r}\right)=\$ 50$, holding cost of the manufacturer $\left(H_{M}\right)=\$ 1.2$ per unit item per unit time, holding cost of the retailer $\left(H_{R}\right)=\$ 1.3$ per unit item per unit time, maximum lifetime of the products $(L)=2$ years, deterioration cost $(w)=\$ 10$ per unit item, material cost $\left(C_{m}\right)=\$ 5$ per unit item, fixed cost at the manufacturer level $\left(F_{C}\right)=\$ 50$, interest charged rate $\left(I_{c}\right)=\$ 0.09$ per year, interest earned rate $\left(I_{e}\right)=\$ 0.07$ per year, $\lambda=500, \delta=25, \eta=28, \mu=600, \xi=2$, $k=1.9, \theta_{1}=1.1, \theta_{2}=1.2$.

By using Wolfram Mathematica 11 software, the obtained optimal results of all cases are given in the Table 2 .

Bold faces of the values in Table 2 shows that Case 1 is profitable for the integrated chain, individually manufacturer and retailer gets more profit in Case 1 and Case 3 respectively with respect to the proposed numerical data. 
The eigenvalues of the Hessian matrix of the integrated average profit function for all the cases are

\begin{tabular}{ll}
\hline Cases & Eigenvalues of the Hessian matrix \\
\hline Case 1 & $(-2809.42,-2433.48,-0.000461)$ \\
Case 2 & $(-2805.83,-2428.34,-0.005044)$ \\
Case 3 & $(-2844.01,-2499.38,-0.002812)$ \\
Case 4 & $(-2849.63,-2517.99,-0.002270)$ \\
Case 5 & $(-2886.84,-2589.14,-0.001669)$ \\
Case 6 & $(-3036.86,-2847.04,-0.001020)$ \\
\hline
\end{tabular}

All the mentioned eigenvalues of the Hessian matrix are negative for all cases. Therefore, for the above solutions, the expected average profit is maximum for all the six cases.

\section{Sensitivity ANALysis}

Here, we conduct the sensitivity of the key parameters for Case 1 with the help of numerical example. The Table 3 reveals how the decision variables, cycle time, manufacturer's average profit, retailer's average profit, and integrated average profit behave with respect to the changes in the key parameters.

The Table 3 shows that:

- The IAP, APR, and $\rho$ increase when the manufacturer offered credit period increases whereas the APM, $Q$, $q$, production run time, and inventory cycle time decreases. Here, the APM decreases as the $Q$ decreases and the credit period offered by manufacturer increases. Again, the $T$ decreases due to the decreasing effect of $Q$. APR increases as the retailer get more credit benefits from the manufacturer. We see that an increasing percentage of APR is less than the decreasing percentage of the APM, but since the average profit of the retailer is much more than the manufacturer, as a consequence IAP is increasing.

- When the retailer offered credit period increases, the APM, $Q$, and $T$ increases whereas the IAP, APR, $q$, and $\rho$ decrease. As the $Q$ increases, the $T$ increases. Since the retailer provides more credit benefits to the customer, the average profit of the retailer decreases. The values of IAP are downwards with the upward values of the retailer's offered credit period, as the APR is much more than the APM.

- The IAP, $Q, T$, and APM increases as interest charged increases, meanwhile $q, \rho$, and APR increases. Due to the reducing effect of $Q$, the $T$ decreases. With the rising values of interest charged, manufacturer profit decreases, and its negative impact reflects on integrated profit.

- A higher interest earned yields higher IAP, higher APR, higher $q$, higher $\rho$, lower $Q$, lower $T$, and lower APM. As the $Q$ decreases, the APM decreases. Again, the average profit of the retailer is much more than the manufacturer, as a result, the IAP increases.

- If the manufacturer increases the production rate then IAP, $q, \rho, Q, T$, and the APM decrease and the APR increases. As the $Q$ decreases, $T$ as well as APM decrease. Since decreasing percentage of APM is much more than increasing percentage of APR, the IAP decreases.

- When the percentage of imperfect production increases, IAP, $q, \rho$, APR decreases whereas $Q$, APM, and $T$ increase. Again, the IAP decreases as the average profit of the retailer is much more than the average profit of the manufacturer.

- When material cost increases, IAP, $q, \rho, Q, T$, and APM decrease, whereas the APR increases. As the $Q$ decreases, $T$ decreases. Since, the average profit increasing percentage rate of the retailer is much less than the decreasing percentage rate of the APM, the IAP decreases with higher values of the material cost.

- APM, $Q$ decrease with the increasing effect of the product life-time. As lot-size decreases, the inventory cycle decreases. Manufacturer average profit decreasing rate is higher than retailer average profit increasing rate, the resultant effect make IAP downwards.

- A higher holding cost at the manufacturer's level yields lower IAP, higher APR, lower APM, lower inventory cycle, higher $\rho$, higher $q$, and lower $Q$. As lot-size decreases, $T$ decreases. The IAP decreases marginally as the decreasing percentage rate of the APM is more than the increasing percentage rate of the APR. 
TABLE 3. Sensitivity of the key parameters.

\begin{tabular}{|c|c|c|c|c|c|c|c|c|}
\hline & \multirow{2}{*}{$\begin{array}{l}\text { Parameter } \\
\text { value }\end{array}$} & \multicolumn{7}{|c|}{ Percentage change of the optimal values } \\
\hline & & $Q^{*}$ & $q^{*}$ & $\rho^{*}$ & $T^{*}$ & $\mathrm{APM}_{1}^{*}$ & $\mathrm{APR}_{1}^{*}$ & $\mathrm{IAP}_{1}^{*}$ \\
\hline \multirow{5}{*}{$M$} & 0.728 & 2.17478 & -0.027477 & -0.027477 & 2.08693 & 0.054965 & -0.043750 & -0.007548 \\
\hline & 0.729 & 1.08842 & -0.013764 & -0.013764 & 1.04495 & 0.027617 & -0.021988 & -0.003796 \\
\hline & 0.731 & -1.09073 & 0.013819 & 0.013819 & -1.04817 & -0.027901 & 0.022223 & 0.003841 \\
\hline & 0.732 & -2.18403 & 0.027697 & 0.027697 & -2.09982 & -0.056103 & 0.044694 & 0.007728 \\
\hline & 0.708 & -2.13438 & 0.027860 & 0.027860 & -2.0521 & -0.051659 & 0.041839 & 0.007550 \\
\hline \multirow[t]{4}{*}{$N$} & 0.709 & -1.06742 & 0.013916 & 0.013916 & -1.02579 & -0.025739 & 0.020840 & 0.003758 \\
\hline & 0.711 & 1.0681 & -0.013893 & -0.013893 & 1.02549 & 0.025570 & -0.02069 & -0.003725 \\
\hline & 0.712 & 2.13713 & -0.027765 & -0.027765 & 2.05089 & 0.050982 & -0.041238 & -0.007418 \\
\hline & 0.088 & 1.55777 & -0.011654 & -0.011654 & 1.49469 & 0.049643 & -0.019489 & 0.005864 \\
\hline \multirow[t]{4}{*}{$I_{c}$} & 0.089 & 0.768634 & -0.005704 & -0.005704 & 0.737761 & 0.024673 & -0.009674 & 0.002922 \\
\hline & 0.091 & -0.749103 & 0.005470 & 0.005470 & -0.71949 & -0.024392 & 0.009542 & -0.002903 \\
\hline & 0.092 & -1.47958 & 0.010717 & 0.010717 & -1.42154 & -0.048518 & 0.018960 & -0.005786 \\
\hline & 0.068 & 0.618591 & -0.008050 & -0.008050 & 0.594026 & 0.014831 & -0.012002 & -0.002162 \\
\hline \multirow[t]{4}{*}{$I_{e}$} & 0.069 & 0.309327 & -0.004027 & -0.004027 & 0.297084 & 0.007424 & -0.006009 & -0.001082 \\
\hline & 0.071 & -0.309396 & 0.004030 & 0.004030 & -0.29723 & -0.007441 & 0.006024 & 0.001086 \\
\hline & 0.072 & -0.618866 & 0.008064 & 0.008064 & -0.594613 & -0.014900 & 0.012063 & 0.002175 \\
\hline & 798 & 3.1001 & 0.010065 & 0.010065 & 3.00085 & 0.096110 & -0.041255 & 0.00 \\
\hline \multirow[t]{4}{*}{$P$} & 799 & 1.49536 & 0.005255 & 0.005241 & 1.44854 & 0.046730 & -0.019930 & 0.004517 \\
\hline & 801 & -1.40002 & -0.005602 & -0.005602 & -1.35795 & -0.044405 & 0.018713 & -0.004434 \\
\hline & 802 & -2.71614 & -0.011492 & -0.011492 & -2.63607 & -0.086748 & 0.036354 & -0.008791 \\
\hline & 0.098 & -2.40318 & 0.202016 & 0.202016 & -2.13835 & -0.020418 & 0.040893 & 0.018408 \\
\hline \multirow[t]{4}{*}{$\alpha$} & 0.099 & -1.23057 & 0.10111 & 0.10111 & -1.0956 & -0.010866 & 0.020800 & 0.009187 \\
\hline & 0.101 & 1.29477 & -0.101355 & -0.101342 & 1.15415 & 0.012320 & -0.021585 & -0.009151 \\
\hline & 0.102 & 2.66106 & -0.20297 & -0.20297 & 2.37352 & 0.0262541 & -0.044044 & -0.018263 \\
\hline & 4.9 & 0.600167 & 0.110938 & 0.110938 & 0.568037 & 0.435412 & -0.005589 & 0.156141 \\
\hline \multirow[t]{4}{*}{$C_{m}$} & 4.95 & 0.294239 & 0.055559 & 0.055559 & 0.278453 & 0.217558 & -0.002713 & 0.078067 \\
\hline & 5.05 & -0.283293 & -0.055726 & -0.055726 & -0.268025 & -0.217278 & 0.002561 & -0.078061 \\
\hline & 5.1 & -0.556316 & -0.111611 & -0.111611 & -0.526263 & -0.434293 & 0.004979 & -0.156117 \\
\hline & 1.98 & 0.506092 & -0.013598 & -0.013598 & 0.460538 & 0.022039 & -0.011089 & 0.001060 \\
\hline \multirow[t]{4}{*}{$L$} & 1.99 & 0.250869 & -0.006751 & -0.006751 & 0.228317 & 0.010942 & -0.005504 & 0.000527 \\
\hline & 2.01 & -0.246642 & 0.006658 & 0.006658 & -0.224527 & -0.010791 & 0.005424 & -0.000522 \\
\hline & 2.02 & -0.48918 & 0.013225 & 0.013225 & -0.445371 & -0.021434 & 0.010771 & -0.001040 \\
\hline & 1.18 & 0.276028 & -0.008085 & -0.008085 & 0.26542 & 0.009511 & -0.003943 & 0.000991 \\
\hline \multirow[t]{4}{*}{$H_{M}$} & 1.19 & 0.137664 & -0.004035 & -0.004035 & 0.132382 & 0.004747 & -0.001967 & 0.000495 \\
\hline & 1.21 & -0.136972 & 0.004021 & 0.004021 & -0.131732 & -0.004730 & 0.001958 & -0.000494 \\
\hline & 1.22 & -0.273258 & 0.008028 & 0.008028 & -0.262819 & -0.009442 & 0.003907 & -0.000988 \\
\hline & 1.28 & 0.437852 & -0.004214 & -0.004214 & 0.420394 & 0.010444 & -0.003420 & 0.001664 \\
\hline \multirow[t]{4}{*}{$H_{R}$} & 1.29 & 0.218116 & -0.002098 & -0.002098 & 0.209439 & 0.005207 & -0.001702 & 0.000831 \\
\hline & 1.31 & -0.216517 & 0.002081 & 0.002081 & -0.207944 & -0.005176 & 0.001687 & -0.000830 \\
\hline & 1.32 & -0.431458 & 0.004146 & 0.004146 & -0.414413 & -0.010322 & 0.003359 & -0.001658 \\
\hline & 9.88 & 2.05923 & -0.032526 & -0.032525 & 1.97661 & 0.055706 & -0.022626 & 0.006101 \\
\hline \multirow[t]{3}{*}{$w$} & 9.94 & 1.00646 & -0.015947 & -0.015947 & 0.966532 & 0.027346 & -0.011047 & 0.003033 \\
\hline & 10.06 & -0.96415 & 0.015368 & 0.015368 & -0.926699 & -0.026417 & 0.01056 & -0.003001 \\
\hline & 10.12 & -1.88946 & 0.030203 & 0.030203 & -1.8168 & -0.051978 & 0.020674 & -0.005970 \\
\hline
\end{tabular}


- A higher holding cost at the retailer's level yields lower IAP, marginal higher APR, lower APM, lower inventory cycle, higher $\rho$, higher $q$, and lower $Q$.

- When the cost of deterioration increases, IAP, APM, inventory cycle time, and $Q$ decrease whereas $q, \rho$, and APR increase. As the decreasing percentage of the APM is much more than the increasing percentage of the APR, the resultant effect decreases the IAP.

\subsection{Managerial insight}

Using this model, the members of a supply chain can determine optimal production lot-size, optimal QIE, and optimal promotional effort, etc. and could earn maximum profit. The proposed model is suitable for bakery product industries, milk product industries and all other manufacturing industries where the produced items deteriorate with time as well as the demand of the products sensitive to QIE and promotional effort.

The under mention conclusions can be noted from the sensitivity analysis of the model.

- With increasing values of the parameters $N$ and $\alpha$, the production lot-size increases and the production lot-size decreases for the increasing values of $M, I_{c}, I_{e}, P, L, H_{M}, H_{R}, C_{m}, k, \xi$, and $w$.

- With the higher values of the parameters $N, \alpha, \xi$, and $C_{m}$, the QIE of the product decreases but the increasing values of the parameters $M, I_{c}, I_{e}, P, L, H_{M}, k, H_{R}$, and $w$ increase the QIE of the product.

- The promotional effort increases when the parameters $M, I_{c}, I_{e}, P, L, H_{M}, H_{R}, \xi$, and $w$ increase and decreases when the parameters $N, \alpha, k$, and $C_{m}$ increase.

- With the rising values of the parameters $N, I_{c}, P, \alpha, L, H_{M}, H_{R}, C_{m}, k, \xi$, and $w$, the integrated average profit is falling down but the integrated average profit is rising up when the parameters $M$ and $I_{e}$ increase.

- Retailer and the manufacturer should suitably adjust the offered credit period to gain the optimal profit.

- When both credit periods provided by the manufacturer and the retailer lie within the manufacturer's cycle, the integrated profit of the chain is maximum.

- The concept of rising imperfect production percentage makes the manufacturer's less profitable, which is not always right. In this context, the production quantity increases enough to meet the expected profit.

- The extended lifetime of the product does not always imply more profit for the integrated system due to lesser production.

- Although, quality effort and promotional effort stimulate the market demand, it is not always economically profitable for the supply chain.

- Higher deterioration cost reflects its negative effect on the manufacturer's profit as well as on integrated profit of the chain.

\section{Conclusion}

Managing inventory for the deteriorating items is a vital factor for every company. Nowadays, every company gives more attention to control the deterioration and to manage the required quality of the products to enhance their market potential. The demand of a product can be boosted by the advertisement of the product as it is used for motivating the consumer to buy the products. On the other hand, trade credit is one of the widespread as well as an acceptable policy for inventory management. Applying this policy, the upper stream member can enhance their market demand and the down-stream member can use the period for their benefit.

By memorizing the above, we have framed a two-layer supply chain model for deteriorating items consisting of a manufacturer and a retailer under a two-stage trade credit policy with variable demand. The production process is not perfect, and some percentage of the produced items are imperfect. We have considered different rates of time-dependent deterioration of the product for the manufacturer and retailer level with the product's fixed lifetime. The retailer and the customer demand have assumed sensitive on the QIE and promotional effort. After formulating an integrated total profit function, we have derived the optimum values of the production lot-size, QIE, and promotional effort so that the integrated profit be maximized. From the numerical section, it is clear that Case 1 is profitable for the integrated chain. By using this model, the manufacturer and the retailer can take optimal decisions on the lot size, QIE, and promotional effort, etc. 
It is observed that the members of the chain have to give more attention to the offered credit period, production rate, material cost and lifetime of the product because the profit of the member can diminish for the wrong decisions on them. This paper reveals that, though QIE and promotional effort stimulates the market demand, it is economically profitable for the supply chain when its plan of activity is carefully designed. The supply chain members have to be more careful about $M, N, P, L, w$ as these parameters are more sensitive compared to others.

We developed this model without including the shortages, market competition, and rework of imperfect items. Further studies can be done by considering selling price-sensitive demand, relaxing zero inventory levels at the terminal point of the total inventory cycle, market competition, and preservative maintenance, etc.

Acknowledgements. The authors would like to express their gratitude to the editors and referees for their valuable suggestions and corrections to enhance the clarity of the article.

\section{REFERENCES}

[1] W. Ahmed and B. Sarkar, Management of next-generation energy using a triple bottom line approach under a supply chain framework. Res. Conserv. Recycl. 150 (2019) 104431.

[2] T. Avinadav, A. Herbon and U. Spiegel, Optimal inventory policy for a perishable item with demand function sensitive to price and time. Int. J. Prod. Econ. 144 (2013) 497-506.

[3] Q. Bai, X. Xu, M. Chen and Q. Luo, A two-echelon supply chain coordination for deteriorating item with a multi-variable continuous demand function. Int. J. Syst. Sci.: Oper. Logistics 2 (2015) 49-62.

[4] L.E. Cárdenas-Barrón and S.S. Sana, A production-inventory model for a two-echelon supply chain when demand is dependent on sales teams' initiatives. Int. J. Prod. Econ. 155 (2014) 249-258.

[5] L.E. Cárdenas-Barrón and S.S. Sana, Multi-item EOQ inventory model in a two-layer supply chain while demand varies with promotional effort. Appl. Math. Modell. 39 (2015) 6725-6737.

[6] T. Chen, Optimizing pricing, replenishment and rework decision for imperfect and deteriorating items in a manufacturer-retailer channel. Int. J. Prod. Econ. 183 (2017) 539-550.

[7] T. Chen and J. Teng, Inventory and credit decisions for time-varying deteriorating items with up-stream and down-stream trade credit financing by discounted cash flow analysis. Eur. J. Oper. Res. 243 (2015) 556-575.

[8] K.J. Chung, S.K. Goyal and Y.F. Huang, The optimal inventory policies under permissible delay in payments depending on the ordering quantity. Int. J. Prod. Econ. 95 (2005) 203-213.

[9] R. Hlioui, A. Gharbi and A. Hajji, Joint supplier selection, production and replenishment of an unreliable manufacturingoriented supply chain. Int. J. Prod. Econ. 187 (2017) 53-67.

[10] C.H. Ho, The optimal integrated inventory policy with price-and-credit-linked demand under two-level trade credit. Comput. Ind. Eng. 60 (2011) 117-126.

[11] Y.F. Huang, Optimal retailer's replenishment decisions in the EPQ model under two levels of trade credit policy. Eur. J. Oper. Res. 176 (2007) 1577-1591.

[12] M.W. Iqbal and B. Sarkar, Recycling of lifetime dependent deteriorated products through different supply chains. RAIRO:OR 53 (2019) 129-156.

[13] C.K. Jaggi, S. Tiwari and S.K. Goel, Credit financing in economic ordering policies for non-instantaneous deteriorating items with price dependent demand and two storage facilities. Ann. Oper. Res. 248 (2017) 253-280.

[14] H. Krishnan, R. Kapuscinski and D.A. Butz, Coordinating contracts for decentralized supply chains with retailer promotional effort. Manage. Sci. 50 (2004) 48-63.

[15] M. Lashgari, A.A. Taleizadeh and S.S. Sana, An inventory control problem for deteriorating items with back-ordering and financial considerations under two levels of trade credit linked to order quantity. J. Ind. Manage. Optim. 12 (2016) 1091-1119.

[16] Z. Lou, X. Lou and F. Hou, Competition and cooperation models for dynamic pricing of perishable products in a two-echelon supply chain. RAIRO:OR $\mathbf{5 5}$ (2021) S2619-S2632.

[17] P. Maa, H. Wang and J. Shang, Supply chain channel strategies with quality and marketing effort-dependent demand. Int. J. Prod. Econ. 144 (2013) 572-581.

[18] R. Maihami, B. Karimi and S.M.T. Ghomi, Effect of two-echelon trade credit on pricing-inventory policy of non-instantaneous deteriorating products with probabilistic demand and deterioration functions. Ann. Oper. Res. 257 (2017) $237-273$.

[19] A. Mandal and B. Pal, Optimizing profit for pricing and advertisement sensitive demand under unreliable production system. To appear in: Int. J. Syst. Sci. Oper. Logistics (2019). DOI: 10.1080/23302674.2019.1646835.

[20] A. Mandal and B. Pal, Unreliable EPQ model with variable demand under two-tier credit financing. J. Ind. Prod. Eng. 37 (2020) $370-386$.

[21] U. Mishra, J. Wu and B. Sarkar, A sustainable production-inventory model for a controllable carbon emissions rate under shortages. J. Cleaner Prod. 256 (2020) 120268.

[22] M. Mishra, S. Hota, S. Ghosh and B. Sarkar, Controlling waste and carbon emission for a sustainable closed-loop supply chain management under a cap-and-trade strategy. Mathematics 8 (2020) 466. 
[23] R. Nandra, A. Majumder and M. Mishra, A multi-retailer sustainable supply chain model with coordination and quality deterioration. RAIRO:OR 55 (2021) S2773-S2794.

[24] J. Noh, J. Kim and B. Sarkar, Stochastic joint replenishment problem with quantity discounts and minimum order constraints. Oper. Res. 19 (2019) 151-178.

[25] B. Pal, Optimal production model with quality sensitive market demand, partial backlogging and permissible delay in payment. RAIRO:OR 52 (2018) 499-512.

[26] B. Pal, S.S. Sana and K.S. Chaudhuri, Three stage trade credit policy in a three-layer supply chain-a production-inventory model. Int. J. Syst. Sci. Oper. Logistics 45 (2014) 1844-1868.

[27] B. Pal, S.S. Sana and K.S. Chaudhuri, Joint pricing and ordering policy for two echelon imperfect production inventory model with two cycles. Int. J. Prod. Econ. 155 (2014) 229-238.

[28] B. Pal, S.S. Sana and K.S. Chaudhuri, Two-echelon manufacturerretailer supply chain strategies with price, quality, and promotional effort sensitive demand. Int. Trans. Oper. Res. 22 (2015) 1071-1095.

[29] B. Pal, S.S. Sana and K.S. Chaudhuri, Coordination contracts for competitive two-echelon supply chain with price and promotional effort sensitive non-linear demand. Int. J. Syst. Sci. Oper. Logistics 2 (2015) 113-124.

[30] B. Pal, S.S. Sana and K.S. Chaudhuri, Two-echelon competitive integrated supply chain model with price and credit period dependent demand. Int. J. Syst. Sci. 47 (2016) 995-1007.

[31] M. Palanivel and R. Uthayakumar, Finite horizon EOQ model for non-instantaneous deteriorating items with price and advertisement dependent demand and partial backlogging under inflation. Int. J. Syst. Sci. 46 (2015) $1762-1773$.

[32] M.A. Rad, F. Khoshalhan, C.H. Glock, Optimal production and distribution policies for a two-stage supply chain with imperfect items and price and advertisement sensitive demand: a note. Appl. Math. Model. 57 (2018) 625-632.

[33] S.S. Sana, An economic production lot Size model in an imperfect production system. Eur. J. Oper. Res. 201 (2010) 158-170.

[34] S.S. Sana, An EOQ model for salesmen's initiatives, stock and price sensitive demand of similar products - A dynamical system. Appl. Math. Comput. 218 (2011) 3277-3288.

[35] S.S. Sana and K.S. Chaudhuri, A deterministic EOQ model with delays in payments and price-discount offers. Eur. J. Oper. Res. 184 (2008) 509-553.

[36] B. Sarkar, Supply chain coordination with variable backorder, inspections, and discount policy for fixed lifetime products. Math. Prob. Eng. 2016 (2016) 6318737.

[37] B. Sarkar, M. Ullah and J. Kim, Environmental and economic assessment of closed-loop supply chain with remanufacturing and returnable transport items. Comput. Ind. Eng. 111 (2017) 148-163.

[38] B. Sarkar, M. Tayyab, N. Kim and M. Habib, Optimal production delivery policies for supplier and manufacturer in a constrained closed-loop supply chain for returnable transport packaging through metaheuristic approach. Comput. Ind. Eng. 135 (2019) 987-1003.

[39] B. Sarkar, M. Ullah and J. Kim, A cooperative advertising collaboration policy in supply chain management under uncertain conditions. Appl. Soft Comput. 88 (2020) 105948.

[40] S.R. Singh and S. Sharma, A production reliable model for deteriorating products with random demand and inflation. Int. J. Syst. Sci.: Oper. Logistics 4 (2017) 330-338.

[41] N.H. Shah and L.E. Cárdenas-Barrón, Retailers decision for ordering and credit policies for deteriorating items when a supplier offers order-linked credit period or cash discount. Appl. Math. Comput. 259 (2015) 569-578.

[42] A.A. Taleizadeh, M. Lashgari, R. Akram and J. Heydari, Imperfect economic production quantity model with upstream trade credit periods linked to raw material order quantity and downstream trade credit periods. Appl. Math. Comput. 40 (2016) $8777-8793$.

[43] J.T. Teng and C.T. Chang, Economic production quantity models for deteriorating items with price- and stock-dependent demand. Comput. Oper. Res. 32 (2005) 297-308.

[44] J.T. Teng and C.T. Chang, Optimal manufacturer's replenishment policies in the EPQ model under two-levels of trade credit policy. Eur. J. Oper. Res. 195 (2009) 358-363.

[45] A. Thangam and R. Uthayakumar, Two-echelon trade credit financing for perishable items in a supply chain when demand depends on both selling price and credit period. Comput. Ind. Eng. 57 (2009) 773-786.

[46] S. Tiwari, L.E. Cárdenas-Barrón, A. Khanna and C.K. Jaggi, Impact of trade credit and inflation on retailer's ordering policies for non-instantaneous deteriorating items in a two-warehouse environment. Int. J. Prod. Econ. 176 (2016) $154-169$.

[47] Y. Tsao and V.T. Linh, Supply chain network designs developed for deteriorating items under conditions of trade credit and partial backordering. Networks Spatial Econ. 16 (2016) 933-956.

[48] Y. Tsao, T. Chen and Q. Zhang, Effects of maintenance policy on an imperfect production system under trade credit. Int. J. Prod. Res. 51 (2013) 1549-1562.

[49] Y. Tsao, Q. Zhang, H. Fang and P. Lee, Two-tiered pricing and ordering for non-instantaneous deteriorating items under trade credit. Oper. Res. 19 (2019) 833-852.

[50] M. Ullah and B. Sarkar, Recovery-channel selection in a hybrid manufacturing-remanufacturing production model with RFID and product quality. Int. J. Prod. Econ. 219 (2020) 360-374.

[51] J. Wu, K. Skouri, J. Teng and L. Ouyang, A note on "optimal replenishment policies for non-instantaneous deteriorating items with price and stock sensitive demand under permissible delay in payment". Int. J. Prod. Econ. 155 (2014) $324-329$.

[52] J. Wu, K. Al-Khateeb, J. Teng and L.E. Cárdenas-Barrón, Inventory models for deteriorating items with maximum lifetime under downstream partial trade credits to credit-risk customers by discounted cash-flow analysis. Int. J. Prod. Econ. 171 (2016) 105-115. 
[53] C. Yang, C. Dye and J. Ding, Optimal dynamic trade credit and preservation technology allocation for a deteriorating inventory model. Comput. Ind. Eng. 87 (2015) 356-369.

[54] C. Zhang, Y. Tian, L. Fan and S. Yang, Optimal ordering policy for a retailer with consideration of customer credit under two-level trade credit financing. To appear in: Oper. Res. (2019). DOI: 10.1007/s12351-019-00505-0. 